\title{
Las Prosperidades Restauradoras: el Papel de las Narrativas Pentecostales en las Estrategias de Gobierno del Sistema Carcelario Argentino
}

\author{
Mauricio Manchado \\ Universidad Nacional de Rosario (UNR), Rosario, Santa Fe, Argentina. E-mail: \\ maurion@steel.com.ar
}

\section{INTRODUCCIÓN}

T a cárcel moderna, en tanto agencia penal destinada a encerrar e in$\perp$ movilizar a un conjunto de personas transgresoras del orden legal, se constituye, vive y sobrevive en base a sus contradicciones. En cuanto a la figura del lenguaje que mejor puede caracterizar ese estado de situación, no logramos, internamente, alcanzar un consenso. Podríamos hablar de la paradoja carcelaria para dar cuenta de una tensa convivencia, en una misma delimitación espacio-temporal de prácticas y discursos que a priori resultarían contradictorios; de la parodia de la resocialización para tratar de comprender cómo algunos conceptos articuladores de la vida en prisión terminan por configurar un escenario de ficcionalizaciones donde es difícil recuperar la potencialidad de los decires y haceres de los actores carcelarios; o, finalmente, podríamos apelar a la aporía del castigo para tratar de comprender cómo los enunciados formales se rearticulan permanentemente con un entramado práctico que poco tiene que ver con ellos, haciendo sumir a la dinámica cotidiana de la prisión en un camino sin salida donde todo fluye al calor de los acontecimientos y con mínimas pautas de regulación de la vida en el encierro.

En ese conjunto de paradojas, parodias y aporías que definen la cotidianeidad de la prisión moderna en Argentina, la religión se inscribe como elemento del viejo, pero nunca abandonado, modelo correccio-

DADOS - Revista de Ciências Sociais, Rio de Janeiro, vol. 60, no1, 2017, pp. 173 a 208. 
nal. Procurando la enmienda del delincuente a los fines de convertirlo en un no-delincuente, la religión logra situarse entre discursos penitenciaristas y cientificistas (positivistas) fundiéndose con la educación, el trabajo y la familia en tanto elementos que buscan enderezar las desviaciones cometidas en el afuera y pretendidamente encausadas por el adentro. Cuando hablamos de religión en el encierro, y particularmente del dispositivo religioso que actualmente predomina en la cotidianeidad de las prisiones argentinas, no estamos hablando del catolicismo, legitimado para funcionar en todas las agencias penitenciarias del país (Algranti, 2012), sino del dispositivo religioso evangélico pentecostal (DREP), cuyos recorridos han sido distantes de los transitados por el católico, permitiéndoles ocupar hoy un lugar preponderante en las escenas de gubernamentalidad de las cárceles en Argentina. Dispositivo que funda su ejercicio en un saber que promueve y efectivamente establece por consenso pautas y normas de relación e interacción social presentadas como alternativas a las predominantes en la cárcel, y cuyo basamento está en los dispositivos culturales del pentecostalismo (narrativas, ritualidades, organización, entre otras), logrando una forma alternativa de regulación social (Miguez en Brardinelli, 2013). Modos de habitar la cárcel no exentos de tensiones, negociaciones, relaciones de fuerza entre las que el detenido se mueve y construye.

En varias ocasiones acceder a un pabellón-iglesia no depende sólo de una decisión o voluntad personal sino también de cómo se gestione, en términos internos y externos, su ingreso a ese topos diferenciado. En algunos casos, por la resonancia de las causas penales, los pabellonesiglesia se presentan como espacios de resguardo solicitados por los representantes legales de los detenidos; en otros, se torna un recurso indispensable para el servicio penitenciario (SP) ante la falta de alternativas al alojamiento de presos conflictivos, por mencionar sólo algunas variables que inciden en la composición y fluctuación de la población encerrada en tales espacios religiosos. Llegar, habitar y permanecer en un pabellón-iglesia remite a un entramado institucional y subjetivo donde deben considerarse tanto las motivaciones personales - que inicialmente pueden estar o no ligadas a la convicción religiosa como las condiciones internas (de la propia cárcel), externas (demandas de las iglesias y otros actores externos), y la combinación de ambas.

El objetivo de este artículo es examinar las narrativas construidas por el dispositivo religioso-evangélico-pentecostal en dos Unidades Peni- 
tenciarias de la provincia de Santa Fe (UP no 3 y UP no 11) centrándonos en el papel que ocupa dicho dispositivo cultural en las tácticas de gubernamentalidad de la prisión ${ }^{1}$. Para ello, describiremos el ordenamiento social de los pabellones-iglesia, examinaremos la división cosmológica espiritual/mundano en la configuración de espacios y subjetividades religiosas en prisión, y analizaremos los discursos que definen a las narrativas pentecostales en el encierro desde la perspectiva de las prosperidades (sanitaria, económica y penal). Se parte del entendimiento de que el entrecruzamiento de esa multiplicidad de elementos nos permitirá comprender cómo este dispositivo cultural narrativo se inscribe en una estrategia integral de gobierno por parte del servicio penitenciario.

La hipótesis central es que existen tres discursos articuladores de la narrativa pentecostal en prisión: económico, sanitario (afectivo) y penal. Éstos actúan en tanto prosperidades que construyen un espacio social desdoblado, rearticulando, en el plano interno, clasificaciones propias de la cosmología religiosa a la cotidianeidad carcelaria, fundiéndose con principios correccionalistas e incapacitantes de la prisión; a la vez que, en el plano externo, reforzando un imaginario sustentado en la continuidad de prácticas y discursos del adentro en el afuera, cristalizado en la intención de las iglesias evangélicas externas de sumar fieles como también en las fragilidades de un discurso sostenido por el contexto en el que se inscribe. Estas tácticas discursivas configuran un espacio - el de los pabellones-iglesia - destacado por la reducción de la conflictividad interna, por la auto-regulación disciplinar de sus habitantes y por una recuperación tanto de los preceptos correccionalistas como incapacitantes que terminan por ocupar un lugar central en la gestión integral de la población encarcelada.

Partiendo de un enfoque cualitativo y de una perspectiva interpretativa (Vasilachis de Gialdino, 2006), el trabajo de campo constó de observaciones participantes y entrevistas en profundidad con detenidos de los pabellones № 2, 5 y 6 de la Unidad Penitenciaria № 11 y los pabellones № 1 y 2 de la Unidad Penitenciaria № 3 de la ciudad de Rosario, todos autodenominados "cristianos" o "iglesias". El acceso al campo debe ser contemplado a la luz de una coyuntura política singular en Santa Fe, iniciada en el año 2008 cuando, al asumir la gestión del gobierno provincial, el Frente Progresista Cívico y Social ${ }^{2}$ promovió, desde la Secretaría de Asuntos Penitenciarios, el "Documento Básico: Hacia una política penitenciaria progresista en la provincia de Santa Fe". 
Dicho programa sentaba bases para las políticas públicas penitenciarias cuyas acciones contemplaban, entre otras, promover la investigación social en cárceles. Tal coyuntura, sumada a la experiencia que veníamos realizando en instituciones de encierro desde 2006 (particularmente en la UP № 3), nos posibilitó el acceso directo - luego de concretar entrevistas con los Directores de los respectivos penales a las cárceles del sur provincial. A pesar de las dificultades en la cotidianeidad del trabajo de campo (demoras en los ingresos, múltiples consultas a estamentos jerárquicos para certificar nuestras autorizaciones, etc.), tuvimos el acceso a los pabellones-iglesia con la posibilidad de permanecer en ellos durante jornadas completas y realizar entrevistas en profundidad con total intimidad, en las celdas de cada detenido y, en muchas ocasiones, a puertas cerradas.

Las observaciones se realizaron tras la participación en instancias rituales desarrolladas en los pabellones-iglesia tales como cultos, pactos y estudios bíblicos, mientras que los entrevistados fueron seleccionados a raíz de dos criterios centrales: tener una estadía mayor a seis meses en la prisión y superar los dos meses en el pabellón-"iglesia". Los entrevistados son hombres de entre 25 y 50 años, habitantes de la ciudad de Rosario y con residencia en los denominados "barrios periféri$\cos ^{\prime \prime}$ de dicha localidad. Sumado a esto, se realizaron entrevistas con el Director, integrantes del equipo profesional y agentes del Servicio Penitenciario de la UP № 11. En el presente artículo referenciaremos algunos registros de campo y entrevistas, pero el cuerpo empírico total del trabajo consta de más de 40 entrevistas en profundidad y cientos de observaciones realizadas durante más de siete años en las dos principales cárceles del sur santafesino ${ }^{3}$.

\section{EL PENTECOSTALISMO CARCELARIO EN ARGENTINA}

El dispositivo, en tanto concepto, se refiere a un conjunto de elementos heterogéneos que comprenden tanto lo discursivo como lo no discursivo (leyes, normativas, espacio, interacciones, etc.), y su constitución está dada a partir de una urgencia que luego va sosteniendo o reconfigurando sus objetivos iniciales (Foucault, 1985). La aparición del dispositivo religioso evangélico pentecostal en contextos de encierro es, precisamente, una respuesta a una urgencia carcelaria en el marco de la transición política entre el período dictatorial (1976-83) y el nuevo orden democrático en Argentina. De este modo, este concepto nos permite articular dos de las dimensiones centrales de su aparición, funciona- 
miento y consolidación. Por una parte, evaluar la diversidad de sus prácticas y discursos que interactúan con disposiciones de la prisión (institución interna) y de la iglesia (institución externa). Por otra, recuperar tanto la dimensión macro como microsociológica del fenómeno, habilitando una lectura de los acontecimientos políticos y sociales acontecidos en Argentina como condiciones de posibilidad para su surgimiento, al tiempo que grilla de intelegibilidad para comprender la dinámica interna de la prisión.

Tras siete años de la dictadura militar más dura y sangrienta de la historia argentina, el período de transición democrática estuvo signado por aperturas y exigencias que el sistema carcelario no pudo ignorar. Las demandas consistieron en reclamos por mayor equidad en la resolución de causas de presos "comunes" ante la conmutación de penas de presos "políticos"; pedidos para que el Servicio Penitenciario abandonara vejaciones y torturas propias del plan sistemático represivo de la dictadura; $y$, correlativamente, la exigencia de mejores condiciones de vida para quienes habitaban las cárceles (salubridad, higiene, actividades, atención judicial, etc.). Sumado a esto, a partir de la transición democrática las relaciones entre penitenciarios y presos empiezan a experimentar un cambio creando "nuevos límites a la posible letalidad de las acciones de los primeros sobre los segundos" provocando que la tortura, mecanismo sistemático utilizado por el régimen dictatorial para amedrentar y asesinar a detenidos en agencias penitenciarias y campos clandestinos de detención-concentración (Calveiro, 1996), sufra una reducción en su magnitud y ubicuidad. Esto no significó una desaparición completa de dichas prácticas, "pero sí una reducción relativa de su presencia" (Miguez, 2008:155-156).

Este período de transición estuvo marcado, en Argentina, por el retorno de juristas, jueces y criminólogos apartados durante la dictadura, que propugnaban la disminución del uso de la prisión. La reaparición de estos actores se materializó en medidas presidenciales volcadas a un primer proceso de descriminalización de acciones consideradas delitos políticos y la inscripción de una lógica descriminalizante sobre sentencias a "presos sociales" o "comunes". En un contexto signado por el hacinamiento, la violencia intramuros, una pesada herencia de estructuras militarizadas y autonomizadas provenientes de la dictadura militar, y una población carcelaria fuertemente politizada, el objetivo del entonces Presidente Ricardo Alfonsín (1983-1989) fue desmilitarizar las cárceles y expandir el estado de derecho. Ante esto, los 
directores de los penales redujeron la disciplina carcelaria e implementaron medidas de apertura intramuros cuyas consecuencias fueron el aumento del poder de los detenidos materializándose, contrariamente a lo esperado, en una importante cantidad de protestas, motines y revueltas (Hathazy, 2015).

Es en ese escenario que el dispositivo religioso evangélico pentecostal comienza a surgir, a finales del 1983, en el Servicio Penitenciario Bonaerense $^{4}$ con la figura de Juan Zucarelli, pastor evangélico que decidió integrarse a las filas del Servicio Penitenciario tras la negativa de las autoridades de la UP № 1 (Olmos, Buenos Aires) a ingresar a dicho penal ante un conflicto cuya consecuencia final fue la muerte de varios presos. A partir de eso Zucarelli se enroló en el SP y pudo ingresar a la cárcel para comenzar con su tarea evangelizadora. Poco a poco fue ganando espacio en un territorio institucional hostil adscrito a la religión católica y a una población detenida que no lograba asimilar su doble condición de pastor-penitenciario. Fue recién en 1985 cuando logró que le otorgaran un pabellón completo para que vivieran allí quienes se habían convertido al evangelismo, o profesaban ese credo antes de la detención. Actualmente el escenario es muy distinto, y aquello que comenzó con 25 detenidos se expandió a miles, ocupando los pabellones-iglesia un lugar tan significativo en la dinámica carcelaria argentina que en el año 2003 la Unidad Penitenciaria № 25 de Lisandro Olmos (provincia de Buenos Aires) fue calificada como la primer cárcel evangélica del mundo ${ }^{5}$.

Credo religioso que en otros países latinoamericanos como Brasil se vio participando, luego de los procesos de laicización del Estado de finales del siglo XIX, en un campo de disputa con el catolicismo donde el locus prisional será enclave estratégico para la distribución de "bienes de salvación a los presidiarios" (Santana Lobo, 2005: 23). Un escenario brasileño que, en ese sentido, combina experiencias religiosas significativas en contextos de encierro como las de la Asociación de Protección y Asistencia a los Condenados (APACs) ${ }^{6}$ de cuño católico (Ordoñez Vargas, 2012), la Iglesia Evangélica Asamblea de Dios de orientación pentecostal (Lenita Scheliga, 2005) o acciones religiosas afro-brasileñas (Rodrigues, 2005), por mencionar algunas de las principales. Este crecimiento del dispositivo religioso evangélico pentecostal carcelario en Brasil data ya de la década de 1990 (Santana Lobo, 2005a) y su presencia supera actualmente, en número e impacto, la de otras religiones en Brasil (Giumbelli, 2013). En Argentina, el retorno 
de la democracia en 1983 será el comienzo de un camino de consolidación del pentecostalismo en las cárceles que en la provincia de Santa Fe tendrá, al menos, tres etapas que van desde el rechazo absoluto a una aceptación relativa del SP, finalizando con prácticas de cooperación/coordinación que nos interrogan sobre las condiciones de posibilidad del DREP como táctica de gubernamentalidad en las cárceles santafesinas.

\section{Emergencias y Alternativas: El Caso de la Provincia de Santa Fe}

El protestantismo primero, y el evangelismo después, en tanto variante de aquella matriz religiosa que se inició en Argentina a comienzos del siglo XX (Bianchi, 2004), fue creciendo en el contexto argentino hasta convertirse hoy, frente a una mayoría católica, en la primera minoría religiosa. Crecimiento que estuvo dado, entre otras cosas, por las estrategias del evangelismo a nivel mundial ${ }^{7}$ y por una atinada lectura de sus representantes locales que vieron en la ebullición social del retorno a la democracia el campo propicio para consolidar un discurso articulado en el resurgimiento, bien como el nacimiento de un "nuevo hombre" (donde se podría leer también un "nuevo país") que debería abandonar viejos pesares para construir un futuro promisorio (Wynarczyk, 2009). Se trata de una lógica cristiana que en términos de acción intramundana empieza a extenderse con más fuerza a espacios sociales "carentes, donde la presencia estatal es difusa o nula". Así, las comunidades evangélicas comienzan a desplegar una "labor social de asistencia y transformación en el ámbito hospitalario, carcelario, en el tratamiento de adicciones y en la asistencia social en las zonas más vulnerables" (Carbonelli y Mosqueira, 2010:114).

Con aquella premisa ingresó Zucarelli al Servicio Penitenciario Bonaerense (SPB) en 1983, y también lo hicieron, con distintas procedencias y trayectorias, los pastores Eduardo Ribello y Oscar Sensini en las prisiones santafesinas. El primero en una situación más ligada a lo azaroso y tras acompañar a un pastor cuyo primo estaba detenido en la Unidad Penitenciaria № 1 de Coronda. Luego de aquella primera visita a la cárcel sintió la necesidad de continuar esa tarea y así lo hace, ininterrumpidamente, desde el año $1986^{8}$. El segundo, inició su labor evangelizadora dos años después y poco a poco fue fundando pabellones-iglesia en la UP № 1, la UP № 3 y distintas comisarías de la ciudad de Rosario?.

Desde aquel entonces los pabellones-iglesia, con vaivenes, fueron creciendo en las distintas cárceles de la provincia de Santa Fe. En los casos 
que analizamos (la UP № 11 y la UP № $3^{10}$ ), la primera vio reducido el porcentaje de pabellones-iglesia a la mitad en los últimos dos años. Los motivos son diversos (cambio en el perfil poblacional, traslados a otras prisiones, etc.), llevando a una reducción de 4 a 2 pabellones-iglesia (de un total de 16) ${ }^{11}$, mientras que en la Unidad nE 3 se mantiene un número estable desde hace más de 10 años; allí 2 de un total de 10 pabellones responden estrictamente al culto evangélico.

Ese es el escenario actual de la provincia de Santa Fe en lo referido a los procesos de inserción, desarrollo y consolidación de los pabellones-iglesia. Un ingreso similarmente conflictivo al de Zucarelli, con un SP reacio a sus ingresos pero que, poco a poco, fue cediendo terreno a partir de una ponderación de resultados (reducción de la violencia intramuros), y de un aporte significativo en lo referido a la gobernabilidad integral de las prisiones. Un Servicio Penitenciario Santafesino (SPS) que, en la actualidad, ha pasado de una aceptación relativa de los pabellones-iglesia y sus dinámicas, a una etapa de cooperación con actores centrales de las iglesias externas e internas tanto que uno de sus pastores, Eduardo Rivello, relata haber sido consultado por autoridades de la Dirección General del Servicio Penitenciario para ocupar, con la iglesia que preside, 2 de los 4 pabellones que funcionan en la Unidad Penitenciaria no 16 (Rosario), última cárcel inaugurada en suelo santafesino.

Tal acción efectivamente se concretó y allí reconocemos cierta especificidad de los vínculos y reciprocidades que caracterizan la presencia del DREP en las prisiones santafesinas. Asimismo, existen singularidades en lo referido a las dinámicas internas de los pabellones-iglesia, particularmente a los roles, funciones, acciones y relaciones de fuerza de quienes habitan los pabellones-iglesia. En ese sentido, no hemos apreciado, por ejemplo, la lógica de abusos y violencia física directa ejercida por los detenidos con jerarquía en tales espacios, descriptas en algunos trabajos sobre el Servicio Penitenciario Bonaerense (Andersen, 2012; Daroqui, 2009), lo que nos lleva a no desestimar esas descripciones, sino más bien a considerarlas para tensionarlas con las del SPS, reconociendo algunas características diferenciales del DREP en las cárceles santafesinas.

\section{NARRATIVAS PENTECOSTALES: ORDENAMIENTO SOCIAL, CLASIFICACIONES Y TENSIONES}

El escenario con el que nos encontramos una vez que el guardia-cárcel del Pabellón № 2 de la Unidad Penitenciaria № 11 nos abre el último 
portón para efectivizar nuestro ingreso es sumamente disruptivo. Para entender el sentido de esta adjetivación sin caer en sobredimensionamientos ni exageraciones, deberíamos decir que en una cárcel de máxima seguridad donde están alojados detenidos calificados de "alta peligrosidad", y en la que su cuerpo general está acusado de cometer irregularidades en lo referido a tratos y modos de gestión de la población (Ganón, 2014), no deja de ser un dato interpelador que el guardia-cárcel proceda llamando a un detenido, le pregunte si puede acompañar al visitante hacia el patio central del pabellón, que éste nos reciba con un apretón de manos antecediendo al "Dios lo bendiga" y que luego de la presentación nos dispongamos a realizar las entrevistas en las celdas a puertas cerradas, todo fuera del alcance de la mirada del vigilante.

A partir de esos gestos, tanto del SP como de los detenidos, se vuelven necesarias preguntas en torno al ordenamiento social (organización, actividades, derechos, obligaciones) que asumen estos espacios dentro de la configuración integral de la prisión. Para comprenderlo, es indispensable recurrir a un juego de analogías donde reconozcamos similitudes con la organización interna del Servicio Penitenciario pero también diferencias a los fines de distinguir las particularidades de los pabellones-iglesia en el esquema integral de la prisión.

La primera analogía es su organización en un esquema jerárquico y verticalista definido de la siguiente forma: siervo-consiervo-coordinadores-líderes-asistentes de líderes-ovejas. Estructura de mando que responde a lineamientos organizacionales de las iglesias pentecostales en el afuera, y donde resultan relativamente innovadoras sus pautas de convivencia. Relativizamos esa calificación porque algunas como no fumar, consumir bebidas alcohólicas y estupefacientes, no insultar, o no escuchar música mundana (cumbia, rock, entre otras) coinciden con el orden ético y moral del pentecostalismo en el afuera, mientras otras como no usar teléfonos celulares (están prohibidos en la prisión) y no portar elementos corto punzantes (cuchillos y chuzas) son propias del contexto de encierro. A su vez, algunas como no agredir a los detenidos y a las autoridades, fundamentalmente al guardia-cárcel, actor más cercano en el día a día carcelario, o tener conversaciones relacionadas a las causas penales por las que están detenidos, es decir, seguir en las "cosas del mundo"12, son objeto de una readaptación de las reglas externas a la cotidianeidad del encierro. 
Los siervos, tienen a su cargo la totalidad del pabellón-iglesia y "velan" por la integridad de todas sus ovejas (y en ese velar se destaca el vigilar que las normas de convivencia sean respetadas y aplicadas). Se ocupan también de dialogar con las autoridades del SP para gestionar beneficios al pabellón que, al mismo tiempo, repliquen en beneficios para el orden carcelario en su conjunto. Asimismo, el siervo se encarga de presidir los rituales religiosos siempre y cuando esté presente en el pabellón. Esta función, en caso de ausencia, se designa a los consiervos que, junto a los coordinadores y líderes, son quienes asisten al siervo y quedan a cargo del pabellón en los momentos en que no está presente. Cumplen la función de vigilar a la población y el seguimiento de las actividades, y están calificados para "instruir en la palabra". Luego nos encontramos con los asistentes de los líderes, cuya función es mediar entre los líderes y las ovejas, asistiendo a los primeros en todo lo que necesitan y haciéndose cargo de los grupos cuando estos no están en el pabellón o en la prisión. Por último, las ovejas son quienes acaban de ingresar o llevan poco tiempo en el pabellón, y se encargan de ejecutar las actividades de limpieza, cocina y culto, entre otras. Las ovejas responden al estamento más bajo y controlado; son estrictamente vigiladas y evaluadas para saber si pueden o no ser ascendidas en los cargos.

Si bien estos esquemas organizacionales se presentan como tipos ideales, no significa que se encuentren completamente autonomizados respecto al funcionamiento integral de la prisión. Su presencia y dinámicas internas se inscriben como táctica de gubernamentalidad para el SP, entendida como la configuración de acciones que buscan "gobernar a alguien", determinar su conducta a partir de un "conjunto de relaciones de poder" y de "las técnicas que permiten el ejercicio de estas" (Foucault, 2014:255-256). Se asume la palabra "gobierno" en su sentido más amplio, tanto en la dimensión de su praxis (qué se hace con los presos, dónde se los encierra, etc.) como en la simbólica (qué estatus se les asigna, qué discursos intervienen en su definición, etc.). Táctica asentada también en mecanismos de reciprocidades formales e informales que se definen como los vínculos que, en la comunidad carcelaria, no se manejan exclusivamente por su supeditación a una estructuración jerárquica sino que la exceden y complementan (Miguez, 2007), habilitando un andar sin demasiados sobresaltos para sus habitantes y un aporte sustancial a la gestión integral de la población encarcelada (Manchado, 2014, 2015a).

Sobre ese esquema organizacional se configuran y definen las narrativas pentecostales en el encierro. Resultantes de una trama cultural his- 
tórica de "significaciones representadas en símbolos" tras las cuales los hombres "comunican, perpetúan y desarrollan sus conocimientos y actitudes frente a la vida" (Geertz, 1997:88), las narrativas procuran darle un sentido de cohesión, unidad y vitalidad a quienes integran los pabellones-iglesia, más allá de que sobre el sintagma "hermanitos", como se los enuncia internamente, se introduzcan variaciones religiosas de validación carcelaria.

Nos referimos a la clasificación de presos-hermanitos en refugiados y/o cachivaches, convencidos y convertidos. Los primeros son quienes viven allí por tener conflictos con detenidos del resto de los pabellones y no poder habitar otro espacio, a excepción de los denominados "buzones"13 o "resguardo"14. A estos se les asigna también el mote de "chaperos" al ser considerados, por el resto de los presos (habitantes de pabellones comunes), como mentirosos o de estar simulando una adscripción a la religión sólo por conveniencia; la iglesia se presentaría así como un refugio y la biblia como escondite (Caldeira Nunes Dias, 2005). Por otro lado, están los "convencidos" que son quienes tienen una larga trayectoria en el encierro y han decidido transitar cierta etapa de la condena alejado de la conflictividad de los pabellones "comunes". En términos generales todos ingresan con esta clasificación, salvo casos excepcionales en los que el SP solicita al siervo que los reciba porque no puede alojarlo ni siquiera en los buzones o en resguardo. Estos casos suelen tener estadías muy breves en los pabellones-iglesia por no soportar ni cumplir con la disciplina interna. Por último, nos encontramos con el "convertido", una de las figuras más difíciles de encuadrar. Estos son quienes no sólo practican la religión con compromiso y demostrando una fuerte arraigo en las creencias y fe pregonadas por las autoridades religiosas externas e internas sino quienes una vez alcanzada la libertad ambulatoria siguen practicando la religión y se alejan de la posibilidad de delinquir.

Este dato es metodológicamente esquivo debido a dos factores. Por un lado, las dificultades para realizar estudios longitudinales que demandan un seguimiento sostenido de sujetos egresados de la prisión y reincorporados a múltiples circuitos sociales, económicos y afectivos. Por otro, porque en caso de querer ceñirnos a los datos estadísticos existentes (que tampoco están construidos oficialmente), contienen una cifra gris respecto a las personas que vuelven a ser detenidas en otros servicios penitenciarios, ya sean bonaerenses o federales ${ }^{15}$. Más allá de estas dificultades, es importante señalar que la categoría de convertido es 
más una auto-denominación que una clasificación impuesta por los otros. La siguiente declaración da cuenta de las dificultades en las que incurre dicha definición, tanto dentro como fuera de la prisión:

Y yo en el nombre de Jesús declaro las cosas por fe, y al tener fe declaras las cosas como son como si fuesen...y yo declaro mi vida que estoy convertido, porque yo quiero llegar a eso, a estar convertido y declaro eso...que Dios me va a convertir y que estoy convertido en el nombre de Jesús (Maximiliano, Pabellón № 2, UP № 11)

Maximiliano está convertido y al mismo tiempo lo estará. Declara que se siente un convertido pero espera que Dios y Jesús lo conviertan, conjugación de tiempos verbales imposibles de fusionar en la sintaxis de una oración pero sí en el devenir paradójico de la vida en el encierro (Manchado, 2015). Tener, ser y querer son modalidades discursivas enrevesadas en conversaciones cotidianas donde la reafirmación del yo se da en función de la mirada de los otros (Goffman, 1997). Conversión que, asimismo, permite centrarnos en uno de los elementos más potentes de la narrativa pentecostal en el encierro (y no sólo en él), es decir, la separación entre lo religioso y lo mundano:

...si vos te comportas delante los ojos de Dios mal no estás creyendo en Dios pero si vos te comportas bien delante de la presencia de Dios con los hermanos... dejas de hablar mal, dejas de acordarte de las cosas del mundo, y dejas de pelear, dejas de tener pensamientos de salir a robar, salir a matar, de salir a tratar de tener todo fácil y vos tenes otros pensamientos entonces quiere decir que algo hay... (Daniel, Pabellón № 5, UP № 11).

Las religiones de salvación en general y la evangélica en particular han promovido siempre esta separación dual entre lo mundano y lo celestial inscribiendo a lo primero como pecaminoso y a lo segundo como bondadoso. Esta separación axiomática funciona en el discurso religioso de los detenidos pero se inscribe en prácticas concretas con matices y desplazamientos (Spadafora en Frigerio, 1994).

Múltiples variables inciden en la definición de lo "mundano" en la prisión. En primer lugar, la variable espacial adquiere especial relevancia. Para el DREP lo mundano se define, en el afuera, como lo pecaminoso en referencia a vicios y consumos (cigarrillo, estupefacientes, alcohol), prácticas ilegales (robar, matar, violar, etc), prácticas amorales (engañar, mentir, faltar el respeto, etc.) o discursos infames (sobre todos 
aquellos dirigidos hacia Dios, o los que hablan sobre cosas que no son de Dios, es decir, todo lo extra-espiritual), donde cada una de estas prácticas pueden ser ejercidas en una multiplicidad de espacios (barrios, discotecas, prostíbulos, instituciones laicas, etc.). En el dispositivo carcelario se produce una condensación de una referencia intra-espacial: los pabellones "comunes". En estos pabellones sucede lo que frecuentemente acontece en la mayoría de las cárceles argentinas: enfrentamientos entre detenidos y de éstos con las autoridades, robos entre presos y a sus visitas, consumo de cigarrillos, estupefacientes y de bebidas alcohólicas caseras, y conversaciones tanto sobre lo sucedido en las causas penales como también lo que sucederá al terminar la condena. Esta proyección, en repetidas ocasiones, tiene como horizonte de posibilidad cometer un nuevo delito. La significación de lo "mundano" para los pabellones-iglesia se condensa entonces en la referencia espacial de todos los pabellones que no son iglesias, sin importar si son de "ingreso", "conducta", si están "a todo ritmo" o si quienes los habitan han consensuado establecer pautas de convivencia para evitar enfrentamientos de todo tipo.

Igualmente, para los hermanitos existe otra referencia espacial: el afuera y la vinculación con las prácticas ilegales y amorales ${ }^{16}$. Quienes habitan las cárceles en Argentina (y esto es un rasgo que se extiende a toda Latinoamérica) reúnen la condición socioeconómica de ser pobres y mayoritariamente habitantes de las periferias urbanas. Allí, aunque no exclusivamente, la resolución de conflictos interpersonales suele estar signada por una "cadena de violencia" (Auyero, 2013) cuyo saldo suele ser la muerte de los implicados. Para los presos-hermanitos, ese mundo que habitaron y experimentaron, es al que no quieren volver y rechazan sistemáticamente. Allí están y estarán las tentaciones que el Diablo o Satanás les pondrá cuando dejen la prisión por ello, es preciso fortalecer la fe intramuros a los fines de que el delito, las drogas, las "malas compañías" (o la junta), la música mundana (cumbias), el ocio, y el desprecio por el otro no se conviertan en una fuerza trascendental que los lleve nuevamente a prisión:

...afuera estaban difícil las cosas, y ya ves que tenemos todo servido afuera, que te está esperando Satanás, con todo servido, con toda la droga, con todo lo que a vos te gusta, el bochinche, las mujeres, la cumbia, lo que lleva la vida de un delincuente (Maximiliano, Pabellón № 2, UP № 11) 
Abandonar el mundo supone abandonar el viejo hombre y desmarcarse de una subjetividad delincuente, ilegal. Cuando en otro momento de sus trayectorias vitales en el encierro (por ejemplo en sus inicios) reforzar una identidad delictiva podía otorgar un lugar de privilegio en la prisión (como también podía otorgársela en el barrio), ahora tal operación es parte de un juego de inversión en el cual es preciso una desidentificación de lo que alguna vez le generó prestigio, tanto dentro como fuera de la cárcel. El DREP consolida la premisa de abandonar el viejo hombre en aras de la aparición de uno nuevo ligado a la espiritualidad, la bondad, la legalidad, en fin, a todo lo que no es calificado como "mundano". Y este proceso de renuncia al mundo lleva, indefectiblemente, a una "transformación del individuo supramundano en el individuo intramundano" (Casanova, 1999: 134), a un gesto de introspección que habilita pensar el cambio, la conversión y rehabilitación ligadas al papel de las prosperidades en el entramado del dispositivo religioso en prisión. Narrativa pentecostal que construye una duplicación del espacio social carcelario: por un lado, enroque con los objetivos correccionalistas e incapacitantes de la prisión (espacio interno) y, por el otro, construcción de imaginarios que procuran reducir las ansiedades e incertidumbres al tiempo que buscan reforzar una estrategia de "reclutamiento" de fieles para las iglesias externas (espacio externo).

Como veremos más adelante, sanidad, economía y liberación son los tres discursos constitutivos de las narrativas pentecostales que buscan no sólo la salvación, sino también la redención y la conversión, propias de las religiones de superioridad moral (Segato, 2008). Éstas "compiten y se esfuerzan por la anexión consistente y continua de cada alma" (Segato, 2008: 66) y de un DREP que inscribe en la cotidianeidad de la prisión una táctica de gubernamentalidad, un modo de conducir la conducta de los otros (Foucault, 2007; 2011), fundada en la reducción de las conflictividades y en la definición de una quiet prison sustentada en la inexistencia de novedades.

\section{LAS PROSPERIDADES RESTAURADORAS: SALUD, DINERO Y LIBERACIÓN}

La teología de la prosperidad se ha convertido en uno de los elementos centrales de la cosmología evangélica (neo)pentecostal ${ }^{17}$. En Argentina, se inserta en una de las etapas más significativas del evangelismo vernáculo: la recuperación democrática en 1983. Las condiciones que hacen posible este crecimiento, también conocido como el "auge evan- 
gélico", son múltiples. Algunas tenían que ver con un contexto político de enorme fragilidad "para reestablecer la institucionalidad democrática republicana" a partir del cual los evangélicos, con la tolerancia del entonces presidente Alfonsín (quien tenía vínculos con organizaciones compuestas por evangélicos como la Asamblea Permanente por los Derechos Humanos, el Movimiento Ecuménico por los Derechos Humanos, y la Comisión Nacional sobre la Desaparición de Personas), hicieron su salida más exitosa a la escena pública entre 1986 y 1990. Esto se produjo en un contexto económico repleto de incertidumbres (una inflación que crecía desmesuradamente), coincidente con la oferta del campo religioso evangélico neo-pentecostal que hablaba de una visitación del Espíritu Santo a Argentina (campaña de unción), y la realización de milagros que liberarían las "ataduras demoníacas y consiguientemente sanidades físicas y mentales" (Wynarczyk, 2009:111).

Entre los principales nombres que estuvieron ligados a este crecimiento y posterior consolidación, a finales de 1980 y principios de 1990, se encuentran Omar Cabrera y su esposa Marfa con la iglesia "Visión de Futuro", Carlos Annacondia con "Mensaje de Salvación" y el pastor Giménez y su esposa Irma con el Ministerio "Ondas de Amor y Paz". Esta etapa de consolidación institucional durante los años 1980 tendría una fuerte eclosión y expansión en términos demográficos y territoriales (Miguez, 2002; Wynarczyk, 2014). Su importancia radicó en la mutación de algunas de las doctrinas y prácticas rituales pentecostales, entre ellas las condensadas "en la doctrina de la 'prosperidad' y la de la 'guerra espiritual'" (Miguez, 2003:190-191). Creencias que dieron lugar a rituales con efectos catárticos donde la batalla entre el bien y el mal era representada de forma dramática y con un fuerte peso en las emociones (Miguez, 2002; Algranti, 2008).

La prosperidad se presenta entonces como discurso articulador de la narrativa pentecostal y si bien autores especializados (Wynarczyk, 2009; Frigerio, 1994; Semán, 1994) suelen tratarla casi exclusivamente en el ámbito económico, proponemos aquí una redefinición en tres prosperidades: sanitaria, económica y penal. Sumado a esto, la unción del poder viene a atravesar a las restantes y hace referencia a un poder "que viene de lo alto y soluciona problemas aquí en la tierra" (Wynarczyk, 2009:142). Las soluciones más frecuentes a las que alude el discurso evangélico, producto de la unción del Espíritu Santo y de una guerra espiritual entablada cotidianamente contra Satanás, es la definición de pequeños milagros en el ámbito, de la salud y la econo- 
mía, entre otros. La teología de la prosperidad económica introduce un conflicto hacia el interior de la cosmología evangélica porque pone entre paréntesis aquella aversión hacia las cosas del mundo, o al menos hace entrar esa histórica negación del mundo en una construcción paradojal según la cual las cosas terrenales, fundamentalmente los bienes materiales, pertenecen a una órbita extra espiritual de la cual deben alejarse pero al mismo tiempo desean; en definitiva, prosperidad económica que lidia con la ética religiosa protestante entre lo terrenal y lo celestial (Weber, 1998, 2007).

En los pabellones-iglesia las prosperidades sanitarias, económicas y penales son fácilmente reconocibles tanto en los enunciados de los detenidos como en las instancias rituales (pactos, estudios bíblicos y cultos) $)^{18}$. Allí se pide, alzando la voz como una confesión asociada a una actitud mental positiva surgida del poder de Jesucristo (Wynarczyk, 2009), por la salud de todos lo que se encuentran alojados en el pabellón y sus familias, por la problemáticas sociales ocurridas fuera de la prisión, por las salidas transitorias de detenidos que habitan el pabellón-iglesia y están frente al desafío del afuera, y por una inmediata resolución de sus causas penales.

Se agarran todos de la mano en círculo y piden por los permisos, los chicos de la calle perdidos en la droga, las madres, por dos chicos puntuales que están saliendo. En el centro de la ronda hay un interno que mira a cada uno de los que conforman el círculo. Pide por la causa de Cristo, por la causa de Enrique y de Guillermo. Son 30 internos. Todos empiezan a balancearse y de un momento a otro comienzan a pedir en voz alta; todas las voces se confunden con los pedidos. Dura aproximadamente dos minutos. Se van levantando las manos y eso es una señal para ir terminando los gritos. El que está en el centro sigue hablando, entremezclándose un amén, con el hijo, espíritu santo, gloria a Dios, y todos aplauden (Registro de campo, Pabellón № 6, UP № 11)

El registro se refiere a uno de los tres pactos realizados diariamente en el Pabellón № 6 de la Unidad Penitenciaria № 11 donde las prosperidades de salud, riqueza y libertad (en términos simbólicos y materiales) se entremezclan continuamente, adquiriendo preponderancia unas y otras en distintas instancias rituales. En un mismo sentido, las prosperidades ocupan un lugar significativo en los enunciados de los detenidos y es a partir de ellos donde reconocemos cómo se articulan internamente sobre un espacio social ${ }^{19}$ con dos dimensiones diferenciadas pero interrelacionadas: 1) hacia los pabellones-iglesia permitiendo el 
sostenimiento y consolidación del argumento del cambio, la transformación, la conversión habilitante de un transitar menos conflictivo en la prisión y una proyección interpeladora de la identidad de delincuente; 2) hacia la prisión en su conjunto porque el argumento del cambio no se convierte en una exigencia institucional o una crítica a la lógica y modos de castigo carcelarios sino que, por el contrario, se integra en una estrategia integral de gobernabilidad, habilitando una reducción de la conflictividad y la configuración de grados de autonomización en lo referido a la administración y gestión de los recursos humanos y materiales.

No afirmamos con eso que las demandas de los pabellones-iglesia hacia el SP sean inexistentes, pero esas demandas están referidas, fundamentalmente, "a la cuestión judicial, de que tal quiere atención, mira que tal tiene que anotar al hijo" (Equipo profesional, UP № 11), es decir, a demandas de funcionamiento interno. $Y$ es que el aporte que los pabellones-iglesia realizan a la gobernabilidad integral de la prisión resulta tan significativo que hasta el propio Director de la UP № 11 sostendrá que "hacen un buen trabajo dentro del servicio" (Director UP № 11).

Prosperidades que en su enunciación fortalecen el viejo pero siempre reactualizado argumento correccionalista (Mouzo, 2014) pero que en sus prácticas y efectos consolidan lógicas incapacitantes y depositarias que sólo procuran sobre el preso encierro, quietismo y sufrimiento (Sozzo, 2009). Mixtura de modelos de encierro que caracterizan a las cárceles argentinas en sus dinámicas concretas desde sus orígenes hasta la actualidad (Caimari, 2004) y que en los pabellones-iglesia, con sus ordenamientos, reciprocidades y narratividades encuentran una de sus más fieles condensaciones.

\section{La Prosperidad en Salud: Consumos y Reconstitución de Lazos Afectivos}

La prosperidad sanitaria es la que menos referencia tiene a la solución de problemas físicos o a enfermedades crónicas (cáncer, HIV, tuberculosis, etc.) de los presos o sus familiares. En su lugar, se destacan otras dos dimensiones muy significativas de la vida en el encierro (aunque no sólo de ella): la reconstitución de los lazos familiares y la recuperación en el campo de las adicciones (fundamentalmente el consumo de estupefacientes). 
Regularidades que enlazan sentidos y discursos con procedencias diferentes pero compatibles en el entramado de los pabellones-iglesia: los religiosos y los penitenciarios. La familia ha sido uno de los elementos constitutivos del modelo correccional en una clave paradojal según la cual la posiciona como contexto promotor del delito y el delincuente pero también factor decisivo para su resocialización. Asimismo, la familia es importante para el mundo de las significaciones religiosas porque dicho concepto articula las prácticas evangélicas tanto dentro como fuera de la cárcel. En los pabellones-iglesia esa transformación suele ser promovida desde los detenidos hacia el resto de los integrantes de la familia, logrando que el núcleo familiar comience a incorporarsea las iglesias externas:

[...] casi cuatro años que no me tomo una pastilla, hace cuatro años que no me tomo una bolsa de merca, hace dos meses que dejé de fumar faso o sea marihuana, hace dos semanas y pico de que pisé este pabellón que dejé el tabaco, todo gracias a Dios porque yo intenté dejarlo por mi fuerza pero nunca pude dejarlo, al contrario, cada vez más adicto me hacía y gracias a Dios pude dejarlo, gracia a Dios mi familia, yo pidiéndole a Dios por mi familia pude ver que Dios me respondió mi oración, mi familia está yendo a la iglesia, mi familia está cambiando también (Cristian, Pabellón № 6, UP № 11)

El enunciado de Cristian es la más clara condensación de cómo la prosperidad en salud articula las dimensiones de la recuperación del núcleo familiar (y hasta su incorporación al mundo espiritual) y de los vicios mundanos vinculados al consumo de cigarrillos y estupefacientes. Pareciera aquí que una cosa deriva en la otra, pero claramente ambas dimensiones pueden funcionar de manera escindida o conjunta. Por tanto, la prosperidad en salud es tanto un restablecimiento de un estado de salud lejano ligado a lo biológico (estar mejor en términos físicos y psíquicos por el abandono del consumo) pero también una prosperidad afectiva que, definitivamente, mejora en términos integrales el andar subjetivo de los detenidos, para soportar el encierro y aliviar sus sufrimientos. Tal como sostiene Geertz, el problema del sufrimiento, como problema religioso, no es el de evitar el sufrimiento sino, paradójicamente, el de cómo sufrir, de cómo hacer de un "dolor físico, de una pérdida personal, de una derrota o de la imponente contemplación de la agonía de otra persona algo tolerable, soportable, algo, como solemos decir, sufrible" (Geertz, 1997:100). En otras palabras, el modo de sufrir está ligado estrechamente al modo de 
transitar el dispositivo religioso, soportando las normas que sostienen a la organización evangélica pentecostal en el encierro a costa de un conjunto de reparaciones y restauraciones que tienen como objetivo al sí mismo y a los otros ${ }^{20}$.

\section{La Prosperidad Económica: Adquisiciones y Proyecciones}

Luego de que Carlos Annacondia, en la década de 1980, estableciera el marco de la unción como dominante para el movimiento social evangélico argentino, los pastores Cabrera y Giménez establecieron el evangelio de la prosperidad como uno de sus pilares en la segunda mitad de esta misma década. El primero enfatizando la "ley de la abundancia", según la cual al "conocer a Cristo Jesús recibimos el poder de cambiar y reemplazar la pobreza por la prosperidad" (Wynarczyk, 2009:143) y el segundo solidificando esta contradicción donde es posible reconocer un rechazo hacia las cosas del mundo y al mismo tiempo desear obtenerlas, avanzar sobre él, "conquistar territorios y gozar de sus bienes", ya sean casas, autos o vacaciones (Wynarcik, 2009).

Los objetivos económicos tienden a ser menos ambiciosos en prisión y a tener más una proyección externa que una pretensión interna. Esto se debe, al menos en parte, a las condiciones materiales de las prisiones argentinas en general y santafesinas en particular, donde resulta escasa la oferta de espacios laborales dentro de las Unidades Penitenciarias (aquí contemplamos tanto trabajos intramuros como extramuros), cuyos peculios no ascienden a más de $\$ 1900$ por mes ${ }^{21}$. Por tanto, la prosperidad económica es referenciada en el discurso de los detenidos a lo que podrán encontrarse una vez egresados de la prisión acaparando esta mención dos variables fundamentales: la posibilidad de sustentarse económicamente sin incurrir en el terreno de lo ilegal y de conseguir un puesto de trabajo a raíz de los contactos (redes sociales) que la iglesia puede otorgar. En cuanto a la primera variable, se mantiene un alto nivel de incertidumbre y se evita ahondar discursivamente con mayor profundidad sobre los medios puestos a disposición para alcanzar tales fines, arraigándose casi exclusivamente en creer que Dios los acompañara una vez egresados de la prisión. Reconocemos allí los desconciertos, sufrimientos y paradojas morales que son el campo de aplicación de las creencias religiosas (Geertz, 1997). El escenario y el panorama post-encierro (y en cierta medida también durante) es absolutamente incierto en lo referente a la esfera económica, posiblemente más de lo que era antes del ingreso a la cárcel. Sin embargo, persiste un 
refuerzo en solicitar y saberse congraciado a futuro por una prosperidad económica que estará por venir:

Dios te mandó unos desafíos en los cuales vos tenes unos proyectos que se ta van a cumplir porque vos recibiste a Cristo en tu corazón y vos vas a tener tu empresa, porque lo imposible que fue para vos estando sin Cristo, Dios te lo va a dar el triple de lo posible, o no, no es que vas a tener una empresa vas a tener tres o cuatro empresas de gente trabajando para vos porque lo que vos anhelas ahora... y que se yo, buscas de Dios para ver qué podes encontrar ahí, Dios te va a dar eso (Fernando, Pabellón № 5, UP № 11)

Por otro lado, la iglesia externa será habilitadora de un primer espacio de contención laboral, no otorgando automáticamente un trabajo remunerado pero sí generando una recepción del detenido en el seno de la iglesia para comenzar -o continuar- con sus tareas de evangelización. Esta puesta a prueba es vista como un gesto de ayuda pero también método de comprobación del cambio, de que los "convertidos" en el tránsito por el encierro finalmente lo son permaneciendo y persistiendo en la iglesia una vez concretados sus egresos. Tal continuidad les abrirá una amplia red social de cooperación donde las ofertas laborales aparecerán, tanto en el mercado informal como formal:

vas a trabajar con nosotros, preparate, acá te vamos a dar un estudio....un seminario para que te prepares para predicar la palabra ¿para qué? Para capacitar a la gente, a los presos, y ahí te preguntan ¿cómo andas...con el... trabajo?...no tengo trabajo, quiero trabajar bueno, yo tengo para que pintes una casa, pinta mi casa, y te da un trabajo ahí y después [...] pinta mi casa, y te pagan, o te dan...te dan una empresa (Fernando, Pabellón № 5, UP № 11)

Es importante resaltar que la trama de continuidades se asienta no sólo en lo que los detenidos creen que sucederá, sino también en lo explicitado por las iglesias externas al definir sus lineamientos de acción. En ese sentido, la Iglesia Redil de Cristo (Pabellón № 1, UP NE 3) sostiene que el objetivo general del Ministerio Carcelario, "es ganar a los privados de su libertad, consolidarlos en Cristo, formarlos como siervos aprobados, discipularlos como hijos y enviarlos a predicar el Mundo." Allí se reconocen expresiones de una "guerra espiritual" implicada no sólo en la conversión de malos en buenos, sino también en estrategias de cooptación de pentecostales en el encierro. 
Así, las prosperidades se entremezclan y conviven bajo cierta armonía. Los relatos de los detenidos, las instancias rituales practicadas en el encierro y las promesas estructurantes de la iglesia externa no establecen delimitaciones tajantes que permitan pensar en prosperidades rechazándose mutuamente. Por el contario, existe una confluencia de prosperidades que habilitan un transitar en el encierro donde tener y ser se diluyen, y el querer se fortalece proyectivamente. Las prosperidades sanitaria y económica trascienden el mero ámbito de enunciación y se sostienen, fundamentalmente, por los imaginarios construidos sobre el afuera. Esto no significa que no cumpla efectos concretos en el adentro ya que recuperarse de las adicciones y alejarse de los enfrentamientos con otros detenidos aumenta las posibilidades de vivir con menos riesgos, como también la iglesia "abre puertas" habilitando espacios de trabajo otorgados a presos que cuentan con buena conducta como los hermanitos. Las relaciones definidas con el SP permiten, de forma directa e indirecta, que los espacios de trabajo más deseados por los detenidos (que se refieren no sólo a los encuadrados en la categoría 1 de peculios sino también a los realizados extramuros) sean otorgados a quienes viven en pabellones-iglesia. Ahora bien, existe una tercera prosperidad que posee una correlación tanto interna como externa: la prosperidad penal. Esta se asocia no sólo a un mejoramiento del tránsito por la prisión (fundamentalmente reduciendo los tiempos de encierro), sino también a dejar de ser aquello que se era, confirmando así, y de manera definitiva, el sentido de la conversión inscripto por el DREP en prisión.

\section{La Prosperidad Penal: El Dios de las Causas y las Libertades}

Las prosperidades que hemos reconocido hasta ahora no tienen disonancia con las promovidas por la narrativa pentecostal en el afuera y hacia el conjunto de la comunidad espiritual evangélica. Pero hay una prosperidad que aparece recurrentemente en las entrevistas y en registros de cultos y pactos que calificamos como prosperidad penal. Esta se refiere a los pedidos por pronta resolución de las causas penales de los procesados, a la posibilidad de acceder a las libertades transitorias sin complicaciones y a la configuración de un escenario futuro donde el delito no sea la opción más inmediata.

Por tanto, sumado a las referencias sobre la prosperidad económica y de salud, son frecuentes también los relatos ligados a la resolución positiva de las causas penales. En ese sentido, se argumenta que ser parte del 
DREP permite una prosperidad penal difícil de comprobar. Allí es donde el pensamiento mágico-religioso adquiere contundencia, desligando de las resoluciones penales a los actores "mundanos" (abogados, fiscales, jueces), poniendo todo el peso de las acciones en un Dios todopoderoso y vaciando el entramado de relaciones, acuerdos, marchas y contramarchas que definen al complejo judicial-penal-carcelario.

Las prosperidades penales se articulan bajo tres modalidades que denominamos procesual, conductual y proyectual. La primera se refiere a cómo actúa el relato de la prosperidad en la resolución de causas penales de detenidos procesados por un conjunto de delitos que, "milagrosamente", son resueltos favorablemente. Dicha resolución alude a la quita de acusaciones en torno a un delito, a la falta de mérito en otros, $\mathrm{o}$ a una revisión de la causa que puede incluso absolver a quien hoy ocupa un lugar en el pabellón-iglesia. Lo significativo del funcionamiento de esta prosperidad penal procesual es que, precisamente, nunca se contempla el proceso. El relato construido sobre la idea del milagro suscita, en la narrativa pentecostal, las dimensiones del efecto y la efectividad. Sucede que la perspectiva religiosa "va más allá de las realidades de la vida cotidiana para moverse en realidades más amplias que corrigen y completan las primeras" (Geertz, 1997:107), y es en esa completitud donde el relato sobre las prosperidades penales se inscribe. Sustentadas por una ritualidad pentecostal que fusiona con gran capacidad simbólica el mundo vivido y el mundo imaginado (Geertz, 1997), logrando que sea un solo mundo, y que ese mundo se vea transformado por gracia de la fuerza religiosa. Gritar y solicitar en cada culto y en cada pacto por la resolución de la causas, tomados todos de la mano, saltando, cantando, ocupando posiciones de acuerdo al Ministerio asignado (de Salvación, de Intercesión, etc), construye un entramado simbólico que fortalece la idea de los "milagros cotidianos" (Daniel, Pabellón № 5, UP № 11). Imposible dejar de pensar el entramado unción y prosperidades como un telón simbólico sobre el que se despliegan las prácticas y discursos de los hermanitos. Sucederá entonces que la prosperidad penal procesual no encontrará explicaciones lógico-racionales pero sí mágicas y milagrosas, como una suerte de devolución de Dios por el trabajo realizado, que se vislumbra ya en términos de restauración:

Yo caí detenido con tres - robos - calificados, estaba buscando de Dios un poco pero no era lo mismo que estar acá [...] y Dios oró en mi vida porque yo ahora empecé a perseverar en el Señor y de esos tres califica- 
dos [...] ahora dos calificados no los tengo más, no están más y...es difícil...vos me decís ¿cómo puede ser? [...] Pero es Dios, porque Dios es el que hace, Dios es el que revierte todos papeles, Dios es el que pone su mano poderosa, entendes, porque uno sigue perseverando y acá de lo que se trata es la fe, mucho, mucho de fe (Martín, Pabellón № 6, UP № 11)

La prosperidad penal conductual contiene, a su vez, una fuerte referencia a la cotidianeidad de los pabellones-iglesia, ya que es una categoría intrínseca a los modos de vida construidos en el encierro, y se vincula a los beneficios otorgados por Dios (y aquí una interesante reformulación del lenguaje penitenciario en el religioso) ante el otorgamiento de "permisos" o salidas transitorias a los que pueden acceder los detenidos con conducta y concepto ejemplar una vez alcanzada la mitad de sus condenas ${ }^{22}$. Aquí el lenguaje mágico no desaparece pero sí tiene una fuente de contrastación ligada a lo terrenal, y es que la dinámica de tensiones, trabas burocráticas, marchas y contramarchas en el otorgamiento de tales permisos es una regularidad que atraviesa a los detenidos de cualquier pabellón. Estos otorgamientos dependen de Juzgados de Ejecución frecuentemente atiborrados de trámites, y permeados por una lógica burocrática (Bourdieu, 2002; De Sousa Santos, 1999; Oszlack, 1984) que sume a la dinámica otorgamiento / no otorgamiento de libertades en un entramado burocrático circunstancial ligado al trabajo de los juzgados, a la celeridad o claridad de los informes de profesionales, a las in-disposiciones de los agentes del Servicio Penitenciario, y al contexto de demandas existentes en las prisiones (huelgas, paros, audiencias individuales y colectivas, etc.). La multiplicidad de elementos intervinientes en el funcionamiento del dispositivo judicial no es menos compleja que la del dispositivo carcelario. De esta manera, si bien los detenidos referencian la ayuda de Dios como imprescindible para destrabar el acceso a las libertades transitorias, lo cierto es que dichas trabas y destrabas deben ser leídas a partir de un entramado burocrático circunstancial que se suma a la relación causal entre buena calificación de conducta de los integrantes de los pabellones-iglesia y el otorgamiento de permisos o salidas transitorias. De allí que el enroque de esos espacios con las tácticas de gubernamentalidad del SP, y que la reducción de la conflictividad interna sea causa y consecuencia de detenidos con buenas calificaciones de conducta:

...hacía un par de días el barón me había compartido que falleció una criaturita, una nena y quería tener un hijo y no podía tener hijos, no po- 
día tener más, no podían tener hijos y que los permisos, no sabía nada, que no sabía cuándo se iba a ir en libertad, y voy a mi celda y le pido a Dios [...] Dios le dio... al toque la mujer quedó embarazada y le bajaron los papeles, los permisos, que ni él sabía cómo le bajaron los permisos si él, él no estaba esperando eso... (Hernán, Pabellón № 5, UP № 11)

La última de las modalidades es la más híbrida de las prosperidades. La prosperidad penal proyectual se refiere, como el propio término lo indica, a una proyección que el detenido hace sobre su vínculo con el delito una vez recuperada la libertad ambulatoria, y en esa proyección ubica a la figura de Dios como respaldo y reaseguro de que no volverá a incurrir en transgresiones. Aquí la prosperidad penal se enrevesa con las demás, ya que para que eso no suceda deben darse condiciones vinculadas al ámbito de la salud (física y afectiva) y económica, sumado a esto la posibilidad de continuar con prácticas religiosas que lo alejen de las tentaciones del mundo. Por ello, la construcción más interesante es la que ubica ahora al delincuente no sólo como un viejo hombre sino en las antípodas morales y éticas de quien ahora se considera un siervo de Dios. No sólo hay un gesto de distanciamiento sino también de estigmatización (Goffman, 2006) que tras un mecanismo discursivo singular pone en el lugar del "otro" los males provocados, asentado un sentido negativo del que él, seguramente, ha sido objeto en otras circunstancias:

...fuimos entendiendo que los homicidas no son de Dios, el ladrón no es de Dios, que hay un infierno y hay un cielo, hago lo malo me voy al infierno, hago lo bueno ante los ojos de Dios y ante tus ojos, te ayudo, te predico que yo trato de que vos creas en Dios para que vos también puedas enseñarle a otro. Yo era un delincuente más en la calle, un homicida más en la calle que acechaba a la ciudad de Villa Gobernador Gálvez y de Rosario, y vos me decís la delincuencia ¿se termina? Yo creo que la delincuencia se termina, yo fui un delincuente que hoy ya no lo soy más. (Daniel, Pabellón № 5, UP № 11)

La visión que ellos tienen -los pastores- la tenemos que tener nosotros, o sea ellos qué ven hoy en día de parte de Dios, ¿ven una cárcel transformada?, bueno, nosotros tenemos que tener esa visión de ver una cárcel transformada, una cárcel que no regenere delincuencia, sino que regenere personas transformadas por Dios, que salgan a la calle, que tengan su familia, una buena educación, que tengan un buen trabajo, un buen sueldo y que sean personas de bien, que cambien (Carlos, Pabellón № 1 y 2, UP № 3) 
Se produce, entonces, un reconocimiento de una pasión restauradora que todo lo puede, de un cambio, una transformación, una rehabilitación que viene a otorgar, de la mano de Dios y de la espiritualidad practicada en la iglesia, la posibilidad de ser "otro" durante el encierro y fuera de él. Eso entronca con los viejos preceptos correccionalistas que la cárcel nunca supo, quiso o pudo aplicar pero a los que sigue apelando, tal vez con menos frecuencia pero con la misma insistencia, cada vez que busca justificar su lugar como modalidad punitiva predilecta de las sociedades modernas.

El DREP inscribe así un conjunto de saberes, entre los que se encuentran las narrativas y sus prosperidades, articulando discursos religiosos con penitenciarios, haciendo convivir la disciplina carcelaria con la eclesiástica, y generando efectos que aportan a la gobernabilidad integral de la prisión más allá de que se lo propongan o no como objetivos manifiestos. La restauración invocada adquiere la doble funcionalidad de, por una parte, reforzar el ideal resocializador que ligó a la religión con la prisión desde los primeros diseños de cárceles modernas y, por otra, contribuir a un ideal incapacitador donde las lógicas "re" van cediendo terreno, paulatinamente, a la lógicas "se": seguridad, severidad y sesgo. En esta distinción que los pabellones-iglesia introducen entre espacios de confinamiento más y menos conflictivos, entre detenidos con buena y mala conducta, entre espacios de religiosidad y peligrosidad se inscribe, para el SP, el sesgo sobre cómo actuar ante el conjunto de la población (de forma más flexible sobre unos y más restrictivo con otros), y el de ser severos con algunas sanciones disciplinarias que pretenden fomentar que nada suceda (sanciones a las que los hermanitos adscriben sin cuestionamientos por su respeto hacia todo aquel que reviste cierta autoridad, sea o no religiosa), es decir, que no existan novedades. Pretensión disciplinar que en las realidades carcelarias locales resulta utópica pero que los pabellones-iglesia habilitan con sus configuraciones culturales, institucionales y relacionales.

Pasión restauradora que oscilante entre la revolución interna del detenido y la conservación del orden de las cosas penitenciarias, hace del movimiento, los cantos, las alabanzas y las palmas un silencio estruendoso que retumba en las paredes de los pabellones-iglesia; gritos que a fin de cuentas refuerzan los silencios. A lomo de sus paradojas la cárcel sigue andando con un dispositivo religioso evangélico pentecostal que hace de sus novedades cotidianas un culto a la ausencia de novedad penitenciaria. 


\section{CONCLUSIONES: PROSPERIDADES IMAGINARIAS Y RESTAURADORAS}

Habitar y transitar un pabellón-iglesia se convierte en una opción otorgada o lograda en el encierro que recupera una de las ideas centrales de la doctrina pentecostal: la que sostiene la concepción de un viejo hombre mundano, terrenal, que ha cometido los actos y excesos que lo depositaron, mantuvieron o regresaron a la prisión y que ahora debe ser olvidado y transmutado en uno nuevo, espiritual, reconvertido. En los textos bíblicos, esta idea puede recuperarse en las palabras que el apóstol Pablo dispensa a los Efesios (Col. 3: 5a- 7): “Haced morir, pues, lo terrenal en vosotros: fornicación, impureza, pasiones desordenadas, malos deseos y avaricia, que es idolatría", y que en el contexto carcelario podemos advertir tanto bajo el enunciado de "morir al orgullo" (abandonar viejas prácticas carcelarias como agredir, consumir estupefacientes, entre otras) como en la continua (auto) apelación al principio correccional de la resocialización.

Delimitación de lo mundano y lo celestial, lo malo y lo bondadoso, constructor de fronteras y distinciones sobre el conjunto de una población cuyo común es la condición de haber transgredido el orden legal. Cosmología que, asimismo, hace pie en una situación de vulnerabilidad e incertidumbre como la atravesada por los detenidos, bajo las promesas estructurantes de la prosperidad económica y en salud (afectiva). Sumado a esto, se argumenta que ser parte del dispositivo religioso-evangélico-pentecostal genera una prosperidad penal que acelera los tiempos del encierro. En la cárcel, el discurso religioso se articula entonces combinando un horizonte de prosperidades económicas, sanitarias (afectivas) y penales.

Sobre ellas y para que las mismas sean efectivas (no en términos de resultados sino de efectos), es significativo el papel que cumplen las formaciones imaginarias, en tanto se fundan sobre dos elementos: la creencia y el deseo. La primera se explica "por el deseo o el fantasma que actúan como a distancia y es precisamente a esa lejanía donde, en última instancia, habrá que llegar" (Mannoni, 1997: 12). Es el lugar que Mannoni le asigna al "aun así" de aquella reconocida frase "ya lo sé, pero aun así", indicadora de una creencia a pesar de que la realidad fáctica nos muestra una escena diferente a la que podemos crear y en la que podemos creer. Algo de esta dinámica se inscribe en la narrativa de los detenidos que habitan los pabellones-iglesia al proyectar hacia "afuera" lo sucedido transitoriamente en el encierro, reconociendo en esos enunciados un "exterior" hostil que estará allí para volver a presentar las tentaciones del Diablo. 
Pero el "aun sí" persiste en una narrativa fundada en prosperidades que permiten construir otra escena en el afuera más cercana al tránsito pacificado de la cárcel que a las conflictividades propias del medio exterior. Creencia que asimismo no funcionaría sin la presencia del otro. Porque el otro es el soporte de nuestra creencia cuando ya nos hemos enfrentando a su confrontación con la realidad. Y ese otro debe ocupar la posición del crédulo, del que todavía cree que es como debería ser aunque efectivamente no sea así. Esos "otros" son precisamente la comunidad de "hermanitos", aquellos que ocupan y rotan permanentemente el lugar del crédulo, indispensable para que la creencia cobre peso y consistencia. Porque lo importante es que "la creencia sobreviva al desmentido, aunque se vuelva incomprensible y aunque no veamos más que sus efectos absolutamente paradójicos" (Mannoni, 1997:19). Lo que atraviesa ambas dimensiones es el deseo de que la realidad no sea como es, y el deseo de ser aquello que no se es. En ese sentido, lo que funciona como creencia, estando encarcelado, son las formaciones imaginarias construidas de acuerdo a los procesos, etapas, trayectorias y espacios que transita el detenido. El de los pabellones-iglesia tiene la particularidad de articular esas creencias y esos deseos sobre una estructura narrativa que funda su potencia en la modalidad discursiva de la promesa; una promesa cristalizada aquí como prosperidades económica, afectiva y penal - proyectivas de un nuevo hombre en el encierro y a pesar de él.

De esta manera, el dispositivo religioso evangélico pentecostal, y en él el conjunto de prosperidades que analizamos, se vincula con los objetivos institucionales de la prisión, tanto con los que históricamente la caracterizaron en sus fauces correccionalistas, como con los incapacitantes. En ese sentido, uno de sus principales papeles es el de presentarse como una táctica de gubernamentalidad que habilita el reaseguro de la seguridad interna. Potenciación de las lógicas "se" y sostenimiento de tal vez el único -o al menos uno de los pocos - logro que las autoridades penitenciarias pueden mostrar: el de que no existan novedades en el día a día carcelario. En una trama carcelaria repleta de tensiones y agresiones, el dispositivo religioso evangélico pentecostal viene a aportar sus saberes, ordenamiento social y narrativas para que "la restauración de todas las cosas" (Hechos 3:21) sean vistas también como el éxito de una gestión penitenciaria que supo integrar a su cotidianeidad aquel saber que nunca supo, pudo o quiso aplicar. O también, podríamos concluir, nunca se dispuso a lograr.

(Recebido para publicação em março de 2016) (Aprovado para publicação em janeiro de 2017) 


\section{NOTAS}

1. El trabajo de campo fue realizado primero, en el marco de una investigación doctoral enfocada en las tácticas discursivas en situaciones de egreso carcelario en la UP №3 -reconociendo allí un importante papel de la religión - y luego en el de nuestro trabajo postdoctoral (2013-2015) y ahora de investigador asistente, en torno al dispositivo religioso como elemento central para pensar las permanentes configuraciones y reconfiguraciones de la subjetividad encerrada.

2. En Septiembre de 2007 el Frente Progresista Cívico y Social (FPCyS) ganó las elecciones provinciales en Santa Fe. El mismo estaba conformado por una alianza partidaria entre la Unión Cívica Radical (UCR), el Partido Demócrata Progresista (PDP), el ARI, el Partido Comunista e Intransigente y el Partido Socialista (PS). Este último dispuso de mayor cantidad de candidaturas en las listas eleccionarias y también las de mayor importancia como, por ejemplo, la del gobernador electo, Dr. Hermes Binner. Meses después, en diciembre de 2007, se inicia efectivamente la gestión y en Abril de 2008 el gobierno presenta, a través de la Secretaría de Asuntos Penitenciarios - perteneciente al Ministerio de Seguridad -, el “Documento Básico. Hacia una política penitenciaria progresista en la Provincia de Santa Fe". El FPCyS ganaría luego las elecciones a gobernador en el año 2011 con la candidatura del Dr. Antonio Bonfatti, como también las últimas correspondientes al período 2015-2019 encabezadas por el actual gobernador de la provincia de Santa Fe, el Ing. Miguel Lifschitz.

3. Este artículo constituye un avance del proyecto de investigación "Transformaciones en las estrategias de gobierno del sistema carcelario argentino: El dispositivo religioso como táctica de gubernamentalidad sobre la población encerrada en el período 1983-2013. El caso del Servicio Penitenciario Santafesino", realizado con financiamiento del Consejo Nacional de Investigaciones Científicas y Técnicas de la República Argentina (Conicet).

4. El sistema carcelario en Argentina se compone de tres servicios penitenciarios, el Servicio Penitenciario Federal (SPF) administrado por el Estado Nacional, el Servicio Penitenciario Bonaerense (SPB) por el gobierno de la provincia de Buenos Aires y los Servicios Penitenciarios Provinciales (SPP).

5. La cárcel recibió el nombre "Cristo la única esperanza" y llegó a tener 250 internos y 30 guardia cárceles, todos evangélicos. En el año 2010, y a partir de una reestructuración del SP lanzada por el entonces Ministro de Justicia de la provincia de Buenos Aires, Ricardo Casal, se convirtió en una prisión para presos valetudinarios.

6. La Asociación de Protección y Asistencia a los Condenados (APAC) es una organización no gubernamental, de cuño católico, que brinda asistencia religiosa a presos en cárceles de Brasil. Se encuentra afiliada a la Fraternidad Brasileña de Asistencia a los Condenados (FBAC), reconocida como entidad de utilidad pública, cuyo objetivo es "orientar, dar cursos, asistir jurídicamente, mantener la unidad de objetivos" (Ordoñez Vargas, 2012: 72). Para una mayor descripción de las características, dinámicas y papeles que asumen las APACs en la gestión del encierro en las cárceles brasileñas, ver Ordoñez Vargas (2012).

7. Impulso dado también en otros países de Latinoamérica llegando a ocupar en algunos de ellos, como el caso de Brasil, lugares significativos en el campo político. Para 
ello, ver Gouvêa Mendonça (1989), Lenita Scheliga (2005), Oro (2011) Campos Machado (2014), entre otros.

8. Actualmente Ribello es pastor de la iglesia interdenominacional "Puertas del Cielo" (en la que confluyen pentecostales, bautistas, nazarenos, entre otros), y posee iglesias en la UP № 1 (Coronda, Santa Fe) como en distintas comisarías de la provincia de Santa Fe.

9. Sensini inauguró a mediados de la década de 1990, junto a su esposa Maricarmen Sensini, la iglesia "Redil de Cristo". De denominación pentecostal, cuenta actualmente con más de 5000 miembros y su sede central está en la zona sur de la ciudad de Rosario.

10. La UP № 3 se encuentra ubicada en el casco céntrico de la ciudad de Rosario, fue inaugurada en 1895 y su perfil institucional, desde el año 2004, es el de ser una cárcel de mediana seguridad donde habitan detenidos que revisten, mayoritariamente, la condición de condenados con penas menores a los 5 años o se encuentran transitando el último período de su condena. Con una población enteramente masculina de 280 personas detenidas, la UP № 3 cuenta con 10 pabellones distribuidos en un sistema arquitectónico radial. La UP № 11 se emplaza en la localidad rural de Piñero, a unos $25 \mathrm{~km}$ de la ciudad de Rosario, cuenta con 16 pabellones y una población total que actualmente es de 700 personas. Calificada como una prisión de máxima seguridad, su población combina detenidos con condenas extensas y otros que, en menor medida, acceden a las libertades transitorias.

11. La reducción de pabellones religiosos en la UP № 11 se vio afectada, entre otras cosas, por el traslado de detenidos que participaban de esos espacios, a la Unidad Penitenciaria NE 6 (Rosario) provocando que esta cuente, actualmente, con un $40 \%$ de pabellones que son iglesias.

12. Para la cosmología evangélica pentecostal las cosas del mundo se refieren a prácticas terrenales tales como consumos de bebidas alcohólicas y estupefacientes, vínculos con el delito, defraudación familiar, prácticas agresivas (físicas y simbólicas), insultar, escuchar música no religiosa (particularmente cumbia), entre algunas de las más señaladas.

13. Se denomina "buzones" a las celdas de castigo y / o disciplinamiento en las que se encierran a los detenidos durante periodos que van desde algunas horas hasta semanas completas. El espacio físico destinado para ello es de 2 × 2 metros y sólo cuenta con una hendija como el buzón de cartas, a través de la cual se entrega la comida y algunos bienes de aseo personal. El detenido suele contar con 1 hora de las 24 hs diarias para salir de dicho espacio.

14. El "resguardo" son celdas destinadas para que el detenido sea cuidado ante una situación conflictiva generada en el pabellón, ya sea con un detenido o con el Servicio Penitenciario. Una vez derivado allí, los equipos de profesionales deben ser informados para ponerse en conocimiento de lo sucedido y generar una estrategia interdisciplinaria que permita volver a ese interno a algunos de los pabellones del penal. Este mecanismo busca resguardar la integridad física del detenido pero también reducir los niveles de abuso por parte del SP.

15. Muchos de los detenidos entrevistados habían estado ya alguna vez en un pabellón-iglesia y ahora encarcelados nuevamente. En aquel entonces habían salido de prisión definiéndose como convertidos y el exterior presentó desafíos que no 
pudieron resolver. Este dato no adquiere más que el carácter de ilustrativo, y sería imprudente realizar conclusiones parciales o totales a partir de él.

16. Si bien referenciamos las variables "adentro" y el "afuera" con fines analíticos es importante considerar que la cárcel no es más que la expresión condensada e intensificada de lo que sucede en la cotidianeidad del afuera (Segato, 2003).

17. Existe una amplia discusión sobre las diferencias entre la cosmología religiosa pentecostal y neo pentecostal. Aquí las nombraremos indistintamente (a pesar de reconocer diferencias) para referirnos a la perspectiva religiosa que se inserta en las prisiones. Para una mayor profundización sobre tales discusiones ver Frigerio (1994).

18. Los cultos, pactos y estudios bíblicos son parte de la liturgia evangélica pentecostal. El primero es la ceremonia colectiva más importante; allí se realizan prédicas y alabanzas, y cada integrante de la iglesia ocupa un rol definido ya sea liderando la ceremonia, cantando o agitando banderas con un carácter fuertemente festivo. El pacto es una oración colectiva compuesta por prédicas y miniprédicas en las que se ruega a Dios, entre otras cosas, por sanidad, liberación y prosperidad, tanto propia como de la familia, con la particularidad de que en prisión se solicita también por la resolución de causas penales. Por último, los estudios bíblicos son reuniones de pequeños grupos en que los líderes seleccionan fragmentos de la Biblia para ser enseñados y analizados. Un relato interesante, en clave etnográfica, sobre la dinámica de los cultos en una cárcel de Brasil es el de Santana Lobo (2005 a) en el Presidio Helio Gómez de Río de Janeiro.

19. El espacio social alude a un espacio pluridimensional "construido en base a principios de diferenciación o de distribución constituidas por el conjunto de las propiedades activas dentro del universo social considerado" (Bourdieu, 1984: 28) en el cual un conjunto de agentes, poseedores de una serie de capitales (culturales, sociales, simbólicos y económicos) definen y disputan sus posiciones dentro de un campo específico.

20. La familia del detenido adopta posiciones sumamente ambivalentes con respecto al tránsito por el pabellón-iglesia. Por una parte, insiste en la necesidad de los cuidados y preservación de la vida durante el encierro pero, al mismo tiempo, puede rechazar la decisión del familiar detenido con el señalamiento de haber abandonado aquellas prácticas vinculadas al "aguante" necesario para construir status dentro de la prisión (y fuera de ella, fundamentalmente en el barrio). Esta situación provoca, en muchas circunstancias, un señalamiento al preso como "chapero" o un distanciamiento concreto (abandono de las visitas) por estar avergonzados de la decisión tomada.

21. Se llama peculio al pago recibido por el preso a cambio de participar de actividades laborales tanto dentro de los muros de la prisión (intramuros) como fuera de ellos (extramuros). A partir de la Resolución NE 488 de Mayo de 2015 del Gobierno de la Provincia de Santa Fe, el peculio en las cárceles santafesinas aumentó en un $300 \%$. Hasta entonces la categoría 1 cobraba $\$ 665$; la categoría 2 \$465 y la categoría 3 \$399, pasando ahora a ser los importes de $\$ 1900, \$ 1500$ y $\$ 1300$ respectivamente. Sumado a esto, las categorías 4 y 5 reciben $\$ 700$ y $\$ 500$ correspondientemente.

22. El término "conducta" se refiere al comportamiento que tiene el detenido sobre las normas carcelarias que rigen el orden (disciplina y convivencia), mientras que "concepto" alude a la evolución personal del preso en el régimen de progresividad, generando esto el parámetro evaluador para conocer sus posibilidades concretas de reinsertarse a la sociedad. 


\section{REFERENCIAS BIBLIOGRÁFICAS}

ALGRANTI, Joaquín. (2008), “Emoción, Dramaturgia y Política. Los Juegos de la Experiencia Religiosa en el Neo-pentecostalismo", en F. Mallimaci (comp.), Modernidad, Religión y Memoria. Buenos Aires, Colihue.

. (2012), “'Cuando ellos Tengan Dos Mil Años, Hablamos!' Sociología de los Capellanes en las Cárceles Bonaerenses". Revista Question, № 36, pp. 1-15.

ANDERSEN, María Jimena. (2012), “Los Pabellones Evangelistas en las Cárceles del Servicio Penitenciario Bonaerense. Antagonismos entre las Perspectivas Micro y Macrosociológica en el Estudio de la Prisión", en Seminario de Estudios Comparados sobre las Estrategias del Gobierno de la Cárcel Neoliberal en Argentina y en Francia, editado por el Grupo de Estudios sobre Derecho Penal y Derechos Humanos, Buenos Aires.

AUYERO, Javier; BERTI, María Fernanda. (2013), Violencia en los Márgenes. Buenos Aires, Katz Editores.

BIANCHI, Susana. (2004), Historia de las Religiones en Argentina. Buenos Aires, Sudamericana.

BOURDIEU, Pierre. (1984), “Espacio Social y Génesis de las Clases”, en Sociología y Cultura. México, Grijalbo.

. (2002), "Espíritus de Estado, Génesis y Estructura del Campo Burocrático", en Razones Prácticas. Sobre la Teoría de la Acción. Barcelona, Anagrama.

BRARDINELLI, Rodolfo. (2013), La Re-invención Religiosa del Encierro: Hermanitos, Refugiados y Cachivaches en los Penales Bonaerenses. Buenos Aires, Ediciones del Centro Cultural de la Cooperación Floreal Gorini y Universidad Nacional de Quilmes.

CAIMARI, Lila. (2004), Apenas un Delincuente: Crimen, Castigo y Cultura en la Argentina, 1880-1955. Buenos Aires, Siglo XXI.

CALVEIRO, Pilar. (1998), Poder y Desaparición. Los Campos de Concentración en la Argentina. Buenos Aires, Colihue.

CAMPOS MACHADO, Maria das Dores; BURITY, Joanildo. (2014), “A Ascensão Política dos Pentecostais no Brasil na Avaliação de Líderes Religiosos". DADOS - Revista de Ciências Sociais, vol. 57, no 3, pp. 601 a 631.

CARBONELLI, Marcos; MOSQUEIRA, Mariela. (2010), “'Militantes del Señor': Cosmología y Praxis Evangélica sobre el Espacio Público". Sociedad y Religión: Sociología, Antropología e Historia de la Religión en el Cono Sur, vol. XX, no 32-33, pp. 108-123.

CASANOVA, José. (1999), "Religiones Públicas y Privadas", en J. Auyero et al. (eds.), Caja de Herramientas: El Lugar de la Cultura en la Sociología Norteamericana. Buenos Aires, Universidad de Quilmes.

DAROQUI, Alcira et al. (2009), “'Dios Agradece su Obediencia': La 'Tercerización' del Gobierno Intramuros en la Cárcel de Olmos". Ponencia presentada y publicada en Actas en el XXVII Congreso ALAS, Buenos Aires.

FOUCAULT, Michel. (1985), “El Juego de Michel Foucault", en El Discurso del Poder. Buenos Aires, Folio Ediciones.

DADOS - Revista de Ciências Sociais, Rio de Janeiro, vol. 60, nº 1, 2017 
. (2007), Seguridad, Territorio, Población: Curso en el Collège de France: 1977-1978. Buenos Aires, Fondo de Cultura Económica.

. (2011), El Gobierno de sí y de los Otros: Curso en el Collège de France: 1982-1983. Buenos Aires, Fondo de Cultura Económica.

. (2014), Obrar Mal, Decir la Verdad: Función de la Confesión en la Justicia. Curso de Lovaina, 1981. Buenos Aires, Siglo Veintiuno.

FRIGERIO, Alejandro (ed.). (1994), El Pentecostalismo en la Argentina. Buenos Aires, Centro Editor de América Latina.

GANÓN, Gabriel. (2014), Informe del Monitoreo de Lugares de Detención Penitenciarios de la Provincia de Santa Fe. Santa Fe, Servicio Público Provincial de Defensa Penal de Santa Fe.

GEERTZ, Clifford. (1997), “La Religión como Sistema Cultural”, en La Interpretación de las Culturas. Barcelona, Gedisa.

GIUMBELLI, Emerson. (2013), “Cultura Pública: Evangélicos y su Presencia en la Sociedad Brasileña”. Sociedad y Religión, vol. XXIII, no 40, pp. 13-43.

GOFFMAN, Erving. (1997), La Presentación de la Persona en la Vida Cotidiana. Buenos Aires, Amorrortu.

. (2006), Estigma: La Identidad Deteriorada. Buenos Aires, Amorrortu.

GOUVÊA MENDONÇA, Antonio. (1989), “Un Panorama de Protestantismo Brasileño Actual". Cuadernos do ISER, no 22, pp. 86-92.

HATHAZY, Paul. (2015), Castigar en Democracia: La Reconstrucción de los Consensos Punitivos de la Pos-transición en los Campos Carcelarios de Argentina y Chile. Ponencia presentada en Seminario Internacional Política y Penalidad. Debates y Perspectivas Contemporáneas. Santa Fe, Universidad Nacional del Litoral/Clacso, 13 y 14 de mayo.

LENITA SCHELIGA, Eva. (2005), “Trajetórias Religiosas e Experiências Prisionais: A Conversão em uma Instituição Penal". Revista Religiões e Prisões, no 61, pp. 75-86.

MANCHADO, Mauricio. (2015), Las Insumisiones Carcelarias: Procesos Comunicacionales y Subjetivos en la Prisión. Rosario, Río Ancho Ediciones

. (2015a), "Dispositivo Religioso y Encierro: Sobre la Gubernamentalidad Carcelaria en Argentina". Revista Mexicana de Sociología, vol. 77, no 2, pp. 275-300.

MANNONI, Octave. (1997), La Otra Escena: Claves de lo Imaginario. Buenos Aires, Amorrortu.

MIGUEZ, Daniel. (2002), “El Protestantismo Popular en la Argentina. Las Lógicas de Expansión del Pentecostalismo en el Siglo XX". Anuario del Instituto de Estudios Histórico Sociales, no 17, Universidad del Centro de Buenos Aires, pp. 163-201.

. (2007), “Reciprocidad y Poder en el Sistema Penal Argentino. Del 'Pitufeo' al Motín de Sierra Chica”, en A. Isla (comp.), En los Márgenes de la Ley: Inseguridad y Violencia en el Cono Sur. Buenos Aires, Paidós.

. (2008), Delito y Cultura: Los Códigos de la Ilegalidad en la Juventud Marginal Urbana. Buenos Aires, Biblos. 
MOUZO, Karina. (2014), “Actualidad del Discurso Resocializador en Argentina”. Revista Crítica Penal y Poder, no 6, pp. 178-193.

NUNES DIAS, Camila Caldeira. (2005), “Evangélicos no Cárcere: Representação de um Papel Desacreditado". Debates do NER, ano 6, no 8, pp. 39-55.

ORDÓÑEZ VARGAS, Laura. (2012), “Humanización Prisional y Religión. Reflexiones a partir del Método de Gestión Carcelaria APAC". Revista de Ciencias Sociales, año 4, no 22, pp. 65-88.

ORO, Ari Pedro. (2011), "Algumas Interpelações do Pentecostalismo no Brasil”. Horizontes Antropológicos, vol. 9, no 22, pp. 383-395.

OSZLACK, Oscar. (1984), “Notas Críticas para una Teoría de la Burocracia Estatal”, en O. Oszlak (comp.), Teoría de la Burocracia Estatal: Enfoques Críticos. Buenos Aires, Paidós.

RODRIGUES, Gilse. (2005), “Transgressão, Controle Social e Religião: Um Estudo Antropológico sobre Práticas Religiosas na Penitenciária Feminina do Estado do Rio Grande do Sul". Debates do NER, ano 6, no 8, pp. 9-20.

SANTANA LOBO, Edileuza. (2005), “Católicos e Evangélicos em Prisões do Rio de Janeiro". Religiões e Prisões, no 61, pp. 22-29.

. (2005a), “Ovelhas Aprisionadas: A Conversão Religiosa e o 'Rebanho do Senhor' nas Prisões". Debates do NER, ano 6, no 8, pp. 73-85.

SEGATO, Rita. (2003), “El Sistema Penal como Pedagogía de la Irresponsabilidad y el Proyecto 'Habla Preso: El Derecho Humano a la Palabra en la Cárcel'". Serie Antropología, Brasil, [Consulta: 16/05/2011]. Disponible en http://vsites.unb.br/ics/dan/ serie_antro.htm

. (2008), “La Faccionalización de la República y el Paisaje Religioso como Índice de una Nueva Territorialidad", en A. Alonso (comp.), América Latina y el Caribe. Territorios Religiosos y Desafíos para el Diálogo. Buenos Aires, Clacso.

SEMÁN, Pablo; WYNARCZYK, Hilario. (1994), “Campo Evangélico y Pentecostalismo en Argentina", en A. Frigerio (comp.), El Pentecostalismo en la Argentina. Buenos Aires, Centro Editor de América Latina.

SOUSA SANTOS, Boaventura de. (1999), "El Estado, el Derecho y la Cuestión Urbana”, en M. R. Neufeld et al. (comp.), Antropología Social y Política, Hegemonía y Poder: El Mundo en Movimiento. Buenos Aires, Eudeba.

SOZZO, Máximo. (2009), "Populismo Punitivo, Proyecto Normalizador y 'Prisión Depósito" en Argentina". Sistema Penal y Violencia, no 1, pp. 33-65.

SPADAFORA, Ana María. (1994), “Creencias Milenaristas e Identidad Religiosa Pentecostal: El Ministerio Ondas de Amor y Paz", en A. Frigerio (comp.), El Pentecostalismo en Argentina. Buenos Aires, Centro Editor de América Latina.

VASILACHIS de GIALDINO, Irene (coord.). (2006), Estrategias de Investigación Cualitativa. Barcelona, Gedisa.

WEBER, Max. (1998), “Teoría de los Estadios y Direcciones del Rechazo Religioso del Mundo", en Ensayos sobre Sociología de la Religión. Madrid, Taurus. . (2007), Ética Protestante y el Espíritu del Capitalismo. Buenos Aires, Gradifco.

DADOS - Revista de Ciências Sociais, Rio de Janeiro, vol. 60, nº 1, 2017 
WYNARCZYK, Hilario. (2009), Ciudadanos de dos Mundos: El Movimiento Evangélico en la Vida Pública Argentina 1980-2001. San Martín, Universidad Nacional de San Martín, UNSAM Edita.

. (2014), Tres Evangelistas Carismáticos: Omar Cabrera, Héctor Aníbal Giménez y Carlos Annacondia. Ciudad Autónoma de Buenos Aires, Fiet-Prensa Ecuménica. 


\section{RESUMO}

As Prosperidades Restauradoras: O Papel das Narrativas Pentecostais nas Estratégias de Gestão do Sistema Penitenciário Argentino

O presente artigo propõe uma análise das narrativas construídas pelo dispositivo religioso evangélico-pentecostal em contextos de encarceramento em relação ao papel que elas desempenham na configuração das táticas de governamentabilidade do sistema penitenciário argentino por parte da administração carcerária. Para tanto, analisamos o ordenamento social assumido pelos pavilhões-igreja, a divisão cosmológica espiritual/mundana na configuração dos espaços e das subjetividades religiosas na prisão, assim como os discursos que definem as narrativas pentecostais em ambiente carcerário enquanto prosperidades (sanitária, econômica e penal). Tomando por exemplo duas prisões da Província de Santa Fé, buscamos por fim compreender as narrativas pentecostais nos pavilhões-igreja e a sua integração a uma estratégia de gestão da população carcerária que, baseada em preceitos de correção e de privação da liberdade, permite a redução dos conflitos e a conformação de uma cadeia operando cotidianamente sem qualquer novidade em suas práticas.

Palavras-chave: narrativa; prosperidades; governamentabilidade; prisão; pentecostalismo

\section{ABSTRACT \\ Restorative Prosperity: The Role of Pentecostal Narratives in Government Strategies Exercised by the Argentine Prison System}

The following article aims to investigate the narratives built by the Pentecostal-evangelical religious device in contexts of confinement in terms of the role they play in government tactics exercised by the prison service in Argentina. To do so, we analyze the techniques of social ordering assumed by church-pavilions, the spiritual/mundane cosmological division in the configuration of religious subjectivities and spaces in prison, and the discourses defining the Pentecostal narratives in confinement as forms of prosperity (whether medical, economic or penal). Taking two prisons in the province of Santa Fe as case studies, we conclude by seeking to understand the Pentecostal narratives in church-pavilions integrated with a government strategy that facilitates the management of the prisoner population, with this strategy based on correctionalist and paralyzing principles which reduce situations of conflict and define a prison service whose day-to-day functioning suffers from a lack of updates.

Key words: narratives; prosperity; governmentality; prison; Pentecostalism 


\section{RÉSUMÉ}

Les Prospérités Restauratrices: Le Rôle des Récits Pentecôtistes dans les Stratégies de Gestion du Système Pénitentiaire Argentin

Le présent article propose d'analyser les récits construits par le dispositif religieux évangélico-pentecôtiste en contextes d'incarcération et le rôle qu'ils jouent dans la configuration des tactiques de gouvernementalité du système pénitentiaire argentin de la part des pouvoirs publics. Pour ce faire, nous avons analysé l'ordonnancement social assumé par les pavillons-églises, la division cosmologique spirituel/mondain dans la configuration des espaces et des subjectivités religieuses en prison, et les discours qui définissent les récits pentecôtistes en milieu carcéral en tant que prospérités (sanitaire, économique et pénale). En prenant pour exemple deux prisons de la province de Santa $\mathrm{Fe}$, nous avons finalement cherché à comprendre les récits pentecôtistes dans les pavillons-églises et leur intégration à une stratégie de gestion de la population carcérale, qui, en se basant sur des préceptes de correction et de privation de liberté, permet la réduction de la conflictualité et la conformation d'une prison qui fonctionne au quotidien sans aucune actualisation des pratiques.

Mots-clés: récit; prospérités; gouvernementalité; prison; pentecôtisme

\section{RESUMEN}

Las Prosperidades Restauradoras: El Papel de las Narrativas Pentecostales en las Estrategias de Gobierno del Sistema Carcelario Argentino

El presente artículo se propone indagar sobre las narrativas construidas por el dispositivo religioso evangélico-pentecostal en contextos de encierro en relación al papel que ocupan con la configuración de tácticas de gubernamentalidad por parte del servicio penitenciario en Argentina. Para ello, son analizados el ordenamiento social que asumen los pabellones-iglesias, la división cosmológica espiritual/mundano en la configuración de espacios y subjetividades religiosas en prisión y, asimismo, los discursos que definen a las narrativas pentecostales en el encierro en tanto que prosperidades (sanitaria, económica y penal). Tomando como casos dos cárceles de la provincia de Santa $\mathrm{Fe}$, se busca, finalmente, comprender las narrativas pentecostales en los pabellonesiglesias integradas a una estrategia de gobierno que habilita la gestión de la población encarcelada, enrocándose con preceptos correccionalistas e incapacitantes cuyos efectos son la reducción de conflictividades y la definición de una cárcel que, en su cotidianidad, funcione sin novedades.

Palabras clave: narrativas; prosperidades; gubernamentalidad; cárcel; pentecostalismo 